serious of these, as with any medical procedure, is of course, death. This is an extremely rare complication and occurs in less than 1 in 100,000 cases. Similarly, and only slightly more frequently, permanent nerve damage can occur. We are prepared to discuss all these complications with you if you wish. You must understand that all precautions are taken to avoid complications and to ensure that you and your baby are safe during your labour and delivery.

Alter you have read this pamphlet, if you wish to discuss any points, please indicate to your obstetrician and he will make arrangements for you to meet with an anaesthetist. You will be required to sign a form indicating that you consent to having the procedure performed and that you have been informed of the risks of the procedure, and have had an opportunity to ask questions of an anaesthetist.

Please understand that the final decision as to whether or not you have an epidural anaesthetic rests with you and your anaesthetist who is performing the procedure. He will base his decision on what he feels is best for you and your baby after consulta. tion with your obstetrician.

Department of Anaesthesia

Dr. Everett Chalmers Hospital

Hôpital Dr. Everett Chalmers

\section{Obstruction of fresh gas flow in an Ayre's T-piece}

\section{To the Editor:}

We would like to report an incident of fresh gas flow failure in an Ayre's T-piece type anaesthetic circuit.

Figure 1 displays a Jackson Rees T-piece with a small crimp in the acute angle of the fresh gas arm.

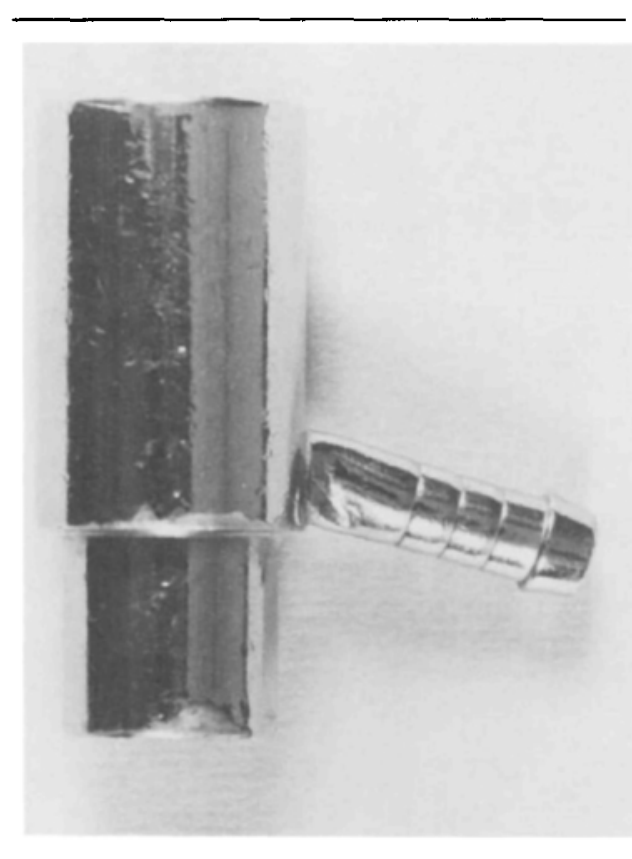

FIGURE 1 T-piece with a small crimp in the acute angle of the fresh gas arm.

This small distortion in the T-piece may have created a site for collection of debris seen in Figure 2. This material occluded the fresh gas arm, leading to complete obstruction of fresh gas flow.

This $T$-piece had been cleaned in an ultrasonic washer, it was then steam autoclaved and packaged for reuse. The material seen in Figure 2 is thought to have accummulated during this cleaning process. Microscopic examination of this debris showed it to be a disorganized fibrous substance; thus, it was not a collection of detergent but most likely some 


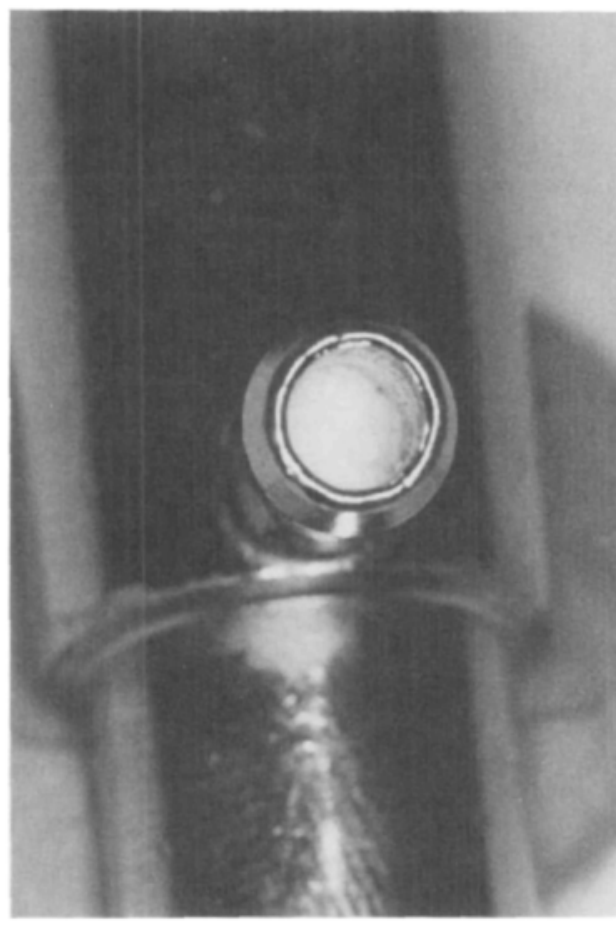

FIGURE 2 Debris completely occludes the fresh gas arm. The damaged arm as seen in Figure 1 may have provided a site for accumulation of this debris.

cloth-like material left behind in one of the cleaning processes.

"Induction of anaesthesia is occasionally accompanied by danger and excitement." In this particular incident such was not the case, as the anaesthetist demonstrated the absence of fresh gas flow through the T-piece prior to induction of anaesthesia. Had the absence of fresh gas flow gone unnoticed, then an anaesthetic mishap might have taken place. Had a high pressure alarm for the detection of obstructed fresh gas flow as described by Doyle and Relton ${ }^{2}$ been in place, a further opportunity for detection would have been available.

Cooper et al. ${ }^{3}$ noted that breathing circuit failures represent 20 per cent of all anaesthetic equipment mishaps. Thus nothing can replace a thorough examination of the breathing circuit prior to each anaesthetic.
In conclusion, we bring to the attention of your readers another cause of gas delivery system failure.

Bruno Bissonnette MD

W.L. Roy MD FRCPC

Department of Anaesthesia

The Hospital for Sick Children

University of Toronto

Toronto, Ontario, M5G 1 X8

\section{REFERENCES}

1 Gregory GA. Pediatric Anesthesia. Churchill Livingstone, New York. Vol. I, 1983, p. 550.

2 Doyle DJ, Relton JES. Technical report: a highpressure alarm for the detection of obstruction of the fresh gas line in the T-piece circuit. Can Anaesth Soc J 1986; 33: 94-6.

3 Cooper JB, Newbower RS, Long CD, McPeek B. Preventable anesthesia mishaps. Anesthesiology 1978; 49: 399-406. 